\title{
DOMAIN FUNGSI KOGNITIF SETELAH TERAPI STIMULASI KOGNITIF
}

\author{
Renata Komalasari $^{1^{*}}$ \\ 1. Fakultas Keperawatan dan Ilmu Kesehatan Universitas Pelita Harapan, Tangerang 15118, Indonesia \\ *E-mail: renata.komalasari@uph.edu
}

\begin{abstract}
Abstrak
Terapi Stimulasi Kelompok (TSK) merupakan terapi kelompok yang terbukti efektif meningkatkan fungsi kognitif lanjut usia dengan demensia ringan-sedang. Penelitian ini bertujuan membuktikan efektifitas TSK dengan 14 sesi terhadap peningkatan fungsi kognitif di Kelurahan Binong, Tangerang, Indonesia. Sebanyak 43 orang mengikuti skrining demensia dengan Mental State Examination (MMSE) rentang. Jumlah responden yang mengukti pretes 24 orang. Attrition rate responden mencapai $79,1 \%$. Hanya lima responden mengikuti TSK hingga pos-tes. Kendati ada kenaikan skor MMSE 2,4 poin antara pre- dan pos-test, namun berdasarkan paired t test, tidak ada perbedaan signifikan antara skor MMSE pre- dan pos-tes secara keseluruhan $(\mathrm{p}=0,080 ; \alpha=0,05)$ dan tidak ada perbedaan pre dan pos-tes untuk tiap domain fungsi kognitif. Kecilnya jumlah sampel dapat memengaruhi hasil penelitian ini. Penelitian lebih lanjut dengan ukuran sampel lebih besar dibutuhkan guna memvalidasi temuan penelitian ini.
\end{abstract}

Kata kunci: fungsi kognitif, lanjut usia (lansia), Mini Mental State Examination (MMSE), terapi stimulasi kognitif

\begin{abstract}
Cognitive Function Domain after Cognitive Stimulation Therapy (CST). CST is a group therapy proved effective at improving cognitive function of the elderly with mild to moderate dementia. The literature hinted no research reports on effectiveness of Cognitive Stimulation Therapy in the Indonesian community. This study aimed to prove effectiveness of CST in the Indonesian community and find which cognitive function domain improved after participating in 14 CST sessions. Purposive sampling was used with inclusion criteria: elderly of 45 and plus, living in Binong, Tangerang, havingmild to moderate dementia (Mental State Examination (MMSE) scores of 10-26, ability to communicate and understand Indonesian language.Attrition rate of respondents was 79,1\%. Only 5 respondentsattended CST upto posttest. While 2,4 point increase was found on MMSE scores between pre-and post-test, paired t testshowed no significant difference between the two $(p=0,080 ; \alpha=0,05)$ and no differences found for each cognitive function domain. Future study is warranted with larger sample size to validate findings of this study.
\end{abstract}

Keywords: cognitive function, cognitive stimulation therapy, elderly, Mini Mental State Examination

\section{Pendahuluan}

Salah satu indikator pemerintahan yang madani adalah adanya peningkatan angka harapan hidup. Jumlah lanjut usia (lansia) di Indonesia meningkat signifikan dari 18,98 juta pada tahun 2007 menjadi 20.547.541 pada tahun 2009 (United States Census Bureau, 2010). Jumlah ini diperkirakan mencapai 28,8 juta $(11,34 \%$ total populasi Indonesia) pada tahun 2020 (Kementerian Sosial Republik Indonesia, 2010). Undang-Undang (UU) Repulik Indonesia Nomor 13 (1998) bab 4 menekankan pentingnya peningkatan angka harapan hidup dan tahun produktif lansia agar mereka dapat hidup secara mandiri dan sejahtera. Hidup sejahtera merupakan hak asasi manusia termasuk kaum lansia. Hal ini bukan hal yang mudah karena seiring dengan penambahan usia makan akan muncul berbagai kondisi degeneratif seperti demensia.

Demensia adalah salah satu kondisi degeneratif yang menyerang otak dan memengaruhi fungsi kognitif lansia. Penderita demensia dapat mengalami penurunan fungsi 
kognitif secara bertahap, sehingga diperlukan perawatan yang berkelanjutan dan menahun.

Gejala demensia mencakup gangguan ingatan, kesulitan menemukan kata-kata dan gangguan dalam proses pikir, perubahan kepribadian atau emosional, penurunan fungsi bahasa atau gangguan dalam berpikir abstrak dan melakukan aktivitas harian di rumah, termasuk merawat diri sendiri (Videbeck, 2001/2008). Oleh karena itu, deteksi dini demensia menjadi salah satu strategi yang dibutuhkan. Deteksi dini demensia memiliki keuntungan antara lain keterjaminan penanganan secara tepat, ada cukup waktu untuk pemanfaatan sumber dukungan, sehingga penderita memiliki waktu untuk membuat keputusan terkait masa depannya (Videbeck, 2001/2008).

Salah satu sumber yang dapat dipertimbangkan adalah terapi stimulasi kognitif yang berfungsi meningkatkan status kognitif lansia. Peningkatan fungsi kognitif pada lansia bukan saja membantu lansia untuk hidup dengan baik dan mandiri (Spector, et al., 2003), tetapi juga meningkatkan produktivitas komunitas secara keseluruhan (Healy, 2004).

Kelurahan Binong, Tangerang, merupakan salah satu rukun warga di lingkungan wilayah Kelurahan Binong yang terdiri dari sembilan rukunwarga (RW). RW 1 yang memiliki populasi 2.737 penduduk, $52 \%$ penduduk memiliki penghasilan keluarga di bawah Rp 1,6 juta per bulan (lihat gambar 1) (FKIK UPH, 2013). Jumlah lansia yang berusia 55 tahun ke atas di tersebut mencapai sekitar 18\%. Pendapatan keluarga yang rendah di daerah ini, menyulitkan para lansia untuk melakukan pola hidup sehat yang dapat mendukung mereka mempertahankan kesehatan yang terus menurun akibat proses alami penuaan, termasuk kemampuan kognitif.

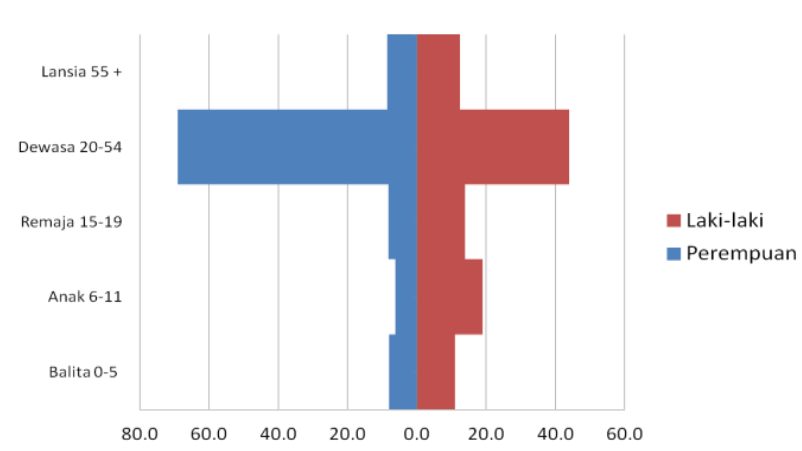

Gambar 1. Karakteristik Penduduk Binong

Program peningkatan produktivitas dan kesejahteraan lansia di masyarakat yang tidak memerlukan biaya besar merupakan suatu alternatif yang dapat dipertimbangkan. Departemen Kesehatan di Inggris menetapkan prioritas nasional untuk meningkatkan akses bagi lansia dengan demensia di negara yaitu terlibat dalam terapi psikososial (Orrell,et al., 2012). Salah satu terapi psikososial yang dapat dipertimbangkan adalah Terapi Stimulasi Kognitif (TSK) karena manfaatnya terbukti setara dengan obat-obatan anti demensia dalam meningkatkan fungsi kognitif dan kualitas hidup (Spector, et al., 2001; 2003; 2006; 2010; \& Streater, 2012).

TSK merupakan terapi kelompok yang dirancang berdasarkan konsep teoretis orientasi realitas untuk menstimulasi kognitif (Spector, et al., 2003). TSK diberikan dalam beberapa sesi. Studi yang telah dilakukan antara lain menggunakan 14, 26 dan 75 sesi (The Evidence-Base, 2013). Terapi yang terdiri dari 14 sesi yang dilakukan dua kali seminggu selama tujuh minggu berturut-turut dengan durasi 45 menit setiap sesi (Spector, et al., 2003) dalam kelompok yang terdiri dari lima orang atau lebih. Diskusi diselenggarakan berdasarkan topik seperti uang, permainan kata, hari ini, dan wajah terkenal (Spector, Orrell, \& Woods, 2010). Penelitian ini bertujuan meneliti domain fungsi kognitif yang meningkat setelah mengikuti 14 sesi TSK di Kelurahan Binong, Tangerang, Indonesia. 


\section{Metode}

Penelitian yang dilakukan di Kelurahan Binong Tangerang ini mendapat izin dari Lembaga Penelitian dan Pengabdian Masyarakat Universitas Pelita Harapan Lippo Karawaci, Banten dan Dinas Kesehatan Kabupaten Tangerang di Tigaraksa, Banten. Penelitian kuasi-eksperimen one group pretest-post-test ini memilih responden dengan teknik pengambilan sampel convenience dengan kriteria inklusi antar lain lansia usia 55 tahun ke atas, tinggal di wilayah kelurahan Binong, mampu berkomunikasi dan memahami bahasa Indonesia, termasuk dalam kategori demensia ringan-sedang (terlihat dari skor Mini Mental State Examination (MMSE) dalam rentang 10-26).

Responden yang memenuhi kriteria inklusi diminta melengkapi MMSE sebelum dan setelah TSK. Skor rata-rata dari enam aspek kogntitif dalam MMSE, yaitu orientasi waktu, orientasi tempat, memori, bahasa, registrasi, dan perhatian dijumlahkan kemudian dihitung nilai reratanya. Nilai rata-rata pre dan pos-tes kemudian dibandingkan dan dianalisis menggunakan paired t test.

Alat ukur yang digunakan adalah MMSE, yang merupakan instrumen yang umum digunakan untuk menilai fungsi kognitif (Folstein, Folstein, \& McHugh, 1975). Penggunaan MMSE cocok untuk golongan usia 18-85 tahun dan telah diterjemahkan ke dalam 10 bahasa (Cormier, Nurius, \& Osborn, 2012). Rentang skor yang bisa diperoleh pada pengukuran MMSE adalah nol sampai 30; skor 27-30 dikategorikan sebagai kognitif normal; 21-26 demensia ringan; 10-20 demensia sedang/moderat; dan $<10$ demensia berat (Alosa Foundation, 2009).

MMSE yang digunakan pada penelitian ini merupakan modifikasi dari MMSE Folstein oleh Universitas Sumatera Utara (tanpa tanggal) yang dikutip dari Kolegium Psikiatri Indonesia (2008). Kelemahan instrumen
MMSE ini adalah orang berasal dari kelompok budaya yang berbeda, atau memiliki pendidikan atau kecerdasan yang rendah mendapatkan skor lebih rendah pada pemeriksaan ini walaupun tidak memiliki gangguan kognitif, sementara orang berpendidikan tinggi mendapat nilai baik walaupun memiliki gangguan kognitif (Folstein, Folstein, \& McHugh, 1975). Alat ukur ini lebih dipilih pada penelitian ini dibanding alat yang lain, seperti ADAS (Alzheimer's Disease Assessment Scale)Cognition (Cog), yang juga bisa digunakan untuk mengukur fungsi kognitif karena instrumen ini telah digunakan dalam berbagai penelitian TSK (Spector, et al., 2003, 2010) juga terbukti dapat diandalkan dan valid untuk mengukur status kognitif pada berbagai penelitian.

TSK yang diberikan pada penelitian ini terdiri dari 14 sesi yang diberikan selama tujuh minggu berturut-turut. Terapi ini menggunakan 'papan orientasi realita' untuk memperlihatkan informasi pribadi dan orientasi, termasuk nama kelompok (dipilih oleh partisipan) untuk memfokuskan dan mengingatkan nama lansia dan menciptakan kesinambungan.

Pada awal tiap sesi, dilakukan aktivitas pemanasan, seperti latihan/olahraga ringan, aktivitas non-kognitif dan orientasi bahwa semua sesi akan dimulai dengan cara yang sama. Proses informasi dititik beratkan dibanding pengetahuan faktual. Sebagai contoh, pada aktivitas 'wajah', pertanyaan yang akan dilempar kepada peserta mencakup "siapa yang terlihat paling muda?" "apa kesamaan yang dimiliki?" Tema seputar masa kecil dan makanan lebih difokuskan guna merangsang proses mengenang atau mengingat kembali (recalling) dan meningkatkan fokus pada masa sekarang. 


\section{Hasil}

Empat puluh tiga (43) responden terskrining berada pada kategori demensia ringan-sedang. Dua puluh empat (24) diantaranya hadir pada pre-tes (yakni sesi ke-1 TSK). Frekuensi kehadiran partisipan TSK dari 24 pada sesi pertama menurun terus sejak sesi ke dua dan tersisa 5 lansia pada sesi ke-14 (Attrition rate responden mencapai 79,1\%). Frekuensi kehadiran kelima peserta ini rata-rata 12,8 kali $(91,4 \%)$.
Tabel 1 menunjukkan bahwa skor MMSE total kelima partisipan mengalami peningkatan ratarata $11,11 \%$ dan Tabel 2 menunjukkan terdapat perbedaan skor rata-rata sebesar 2,4 poin. Tidak ada perbedaan signifikan antara skor MMSE pre dan pos-tes secara keseluruhan ( $p=0,080 ; \alpha=0,05)$, begitu juga tidak ada perbedaan signifikan skor MMSE antara pre- dan pos-tes per domain fungsi kognitif (orientasi waktu, orientasi tempat, memori, bahasa, registrasi, dan perhatian). Tabel 3 menunjukkan perbedaan fungsi kognitif peserta per domain.

Tabel 1. Peningkatan Skor MMSE Sebelum dan Setelah Terapi Stimulasi Kognitif

\begin{tabular}{cccc}
\hline MMSE Pre-Tes & MMSE Pos-Tes & Peningkatan Skor (d) & Kenaikan Rerata (\%) \\
\hline 24 & 27 & 3 & \\
22 & 23 & 1 & $2,4(11,11 \%)$ \\
23 & 25 & 2 & \\
17 & 17 & 0 & \\
22 & 28 & 6 & \\
\hline
\end{tabular}

Tabel 2. Perbedaan Skor MMSE Sebelum dan Setelah Terapi Stimulasi Kognitif

\begin{tabular}{lcccc}
\hline & $\begin{array}{c}\text { Rerata Pre-tes } \\
(\mathbf{9 5 \%} \text { IK) }\end{array}$ & $\begin{array}{c}\text { Rerata Pos-tes } \\
(\mathbf{9 5 \%} \text { IK) }\end{array}$ & $\begin{array}{c}\text { \% Perbedaan Skor } \\
\text { Rerata (95\% IK) }\end{array}$ & Nilai p \\
\hline Fungsi Kognitif & $21,6(2,71)$ & $24,00(4,36)$ & $2,4(2,3)$ & 0,08 \\
\hline
\end{tabular}

Tabel 3. Perbedaan Skor MMSE Per Domain Sebelum dan Setelah Terapi Stimulasi Kognitif

\begin{tabular}{lcccc}
\hline \multicolumn{1}{c}{ Fungsi Kognitif } & $\begin{array}{c}\text { RerataSkor Pre- } \\
\text { tes }\end{array}$ & $\begin{array}{c}\text { RerataSkor Pos- } \\
\text { tes }\end{array}$ & $\begin{array}{c}\text { Perbedaan Skor } \\
\text { Rerata }\end{array}$ & Nilai p \\
\hline Orientasi Waktu & 2,6 & 4 & 1,4 & 0,052 \\
Orientasi Tempat & 2,6 & 3 & 4,0 & 0,374 \\
Registrasi & 2,6 & 2,8 & 0,2 & 0,374 \\
Perhatian & 3,2 & 4 & 0,8 & 0,477 \\
Memori & 2,4 & 2,8 & 1,34 & 0,541 \\
\hline
\end{tabular}

\section{Pembahasan}

TSK merupakan terapi kelompok yang melibatkan partisipan dalam rangkaian kegiatan dan diskusi yang bertujuan untuk meningkatkan fungsi kognitif dan sosial (Clare \& Woods, 2004).Terapi ini terdiri dari 14 sesi yang dilakukan dua kali setiap minggu selama tujuh minggu berturut-turut dengan durasi 45 menit setiap sesi (Spector, et al., 2003). Banyak penelitian membuktikan bahwa keterlibatan dalam TSK bermanfaat untuk dua hal, yakni kualitas hidup dan fungsi kognitif (Spector, et al., 2003). Penelitian di Binong ini memfokuskan pada pengaruh TSK terhadap fungsi kognitif.

Penelitian Binong ini menunjukkan bahwa kendati secara statistik tidak ada perbedaan signifikan pada fungsi kognitif lansia secara keseluruhan (overall) antara sebelum dan setelah mengikuti TSK, namun terdapat 
peningkatan skor MMSE setelah lansia mengikuti TSK. Hasil penelitian ini sejalan dengan kebanyakan bukti literatur tentang keefektifan terapi stimulasi kognitif (Spector,et al., 2001; 2003; 2006; 2010). Terapi kelompok ini telah mendapatkan pengakuan sebagai terapi alternatif selain terapi farmakologis untuk orang dengan demensia ringan sampai sedang (Spector, et al., 2003; 2010). Manfaat TSK telah ditetapkan sebagai intervensi psikologis untuk penderita demensia (Brooker \& Duce, 2000; Eloniemi-Sulkava, 2001; Baker, et al., 2003; Brodaty, Green, \& Koschera, 2003; Spector, et al., 2003; Livingston, Johnston, Katona, Paton, \& Constantine, 2005).

Di antara intervensi tersebut, terapi stimulasi kognitif (TSK) terbukti menawarkan hasil yang paling memuaskan (Breuil, De Rotrou, \& Forette, 1994), sehingga semakin dikenal sebagai penangan alternatif bagi penderita demensia karena bukan saja meningkatkan fungsi kognitif pada penderita demensia ringan-sedang, tetapi juga efeknya setara dengan beberapa obat-obatan psikotropika seperti astetilkolin (Spector, et al., 2003). Bahkan Woods, et al., (2009), dalam kajian Cochrane-nya terhadap 9 penelitian $R C T$ (bukti penelitian level tertinggi) menyimpulkan bahwa keefektifan TSK saat ini diakui melebihi efek obat-obatan.

Hasil penelitian juga menunjukkan tidak ada perbedaan skor pre dan pos-tes untuk setiap domain fungsi kognitif (orientasi waktu, tempat, registrasi, perhatian dan memori). Hal ini berbeda dari hasil penelitian dengan metode randomised controlled trial (RCT) pertama yang meneliti efektivitas TSK oleh Breuill, et al., (1994) yang mengungkapkan bahwa peningkatan skor MMSE terjadi pada kemampuan mengingat daftar kata (fungsi memori). Penelitian juga menunjukkan adanya perubahan signifikan pada skor MMSE setelah TSK dilakukan. Selain menggunakan MMSE sebagai alat ukur neuropsikologis untuk mengevaluasi beberapa luaran, Breuil, et al.,
(1994) juga menggunakan alat ukur Uji Memori Daftar Kata.

Manfaat yang dialami lansia dari TSK ini berkaitan dengan prinsip orientasi realitas yang diterapkan dalam TSK, meliputi: menstimulasi bagian-bagian otak, mengaktifkan pikiran dan kognitif, melatih keterampilan yang tidak digunakan lagi, aktivitas yg memotivasi lansia melakukan upaya, aktivitas tidak terlalu sulit, menghindari merasa tak mampu, menenekankan pada opini lebih dari fakta, menggunakant triggers dan prompts untuk membantu pemahaman, misal pada kegiatan "Bunyi", lansia diminta mengidentifikasi suara dibantu melihat gambar, pada kegiatan "Makanan", lansia dibantu dengan kecap, bau, dan rasakan tekstur (nanas), konsentrasi dibantu dengan melihat dan menyentuh, menggunakan gambar berwarna untuk menunjukkan gambar, seperti alat musik, wajah tokoh, benda-benda antik (Spector, et al., 2003).

Kelemahan penelitian ini adalah sampel kecil $(n=5)$, sehingga dapat berkontribusi sebagai penyebab tidak signifikannya hasil uji beda skor MMSE sebelum dan setelah terapi. Jumlah sampel yang besar dapat meningkatkan kekuatan hasil penelitian (Schneider, et al., 2007). Oleh karena itu, penelitian lebih lanjut tentang keefektivan TSK dalam masyarakat Indonesia dengan sampel yang lebih besar dibutuhkan untuk mengonfirmasi keefektifan terapi stimulasi kognitif pada lansia dengan demensia ringan-sedang.

Modifikasi alat dan bahan atau materi TSK per sesi dari preskripsi manual juga dapat menjadi faktor kontributor tidak signifikannya perbedaan skor MMSE sebelum dan setelah terapi. Modifikasi ini tidak dapat dihindari mengingat beberapa alat dan bahan pada manual TSK tidak atau sulit ditemukan di lingkungan masyarakat Indonesia. Perbedaan karakteristik responden juga dapat menjadi penyebab. Sesi-sesi TSK sebenarnya didesain untuk partisipan yang mampu baca tulis. Akan 
tetapi, pada penelitian ini lima peserta TSK tidak mampu membaca dan menulis, sehingga beberapa sesi diubah untuk mengakomodasi kondisi ini. Peneliti juga harus membacakan instruksi pada form MMSE kepada responden dan kemudian responden menyampaikan jawaban secara lisan.

Keterbatasan lainnya adalah penelitian ini tidak menguji faktor lain yang mungkin saja berinteraksi dengan fungsi kognitif pada lansia dengan demensia. Berbagai faktor yang menyebabkan responden tidak menyelesaikan terapi hingga tahap akhir atau post tes juga tidak diidentifikasi.

\section{Kesimpulan}

Penelitian ini memfokuskan pada pengaruh TSK terhadap fungsi kognitif. Penelitian ini menunjukkan bahwa dengan terlibat dalam 14 sesi TSK yang berprinsip pada kegiatan orientasi realitas, fungsi kognitif lanjut usia dengan demensia ringan-sedang dapat meningkat. Penelitian ini menunjukkan bahwa penerapan TSK pada lansia dengan demensia di Indonesia tidaklah mudah. Diperlukan beberapa modifikasi agar terapi dapat diselesaikan.

Penelitian lebih lanjut dengan melibatkanlanjut usia dengan jumlahlebih besar dan di tempat yang berbeda perlu dilakukan sebelum temuan keefektifan TSK dapat digeneralisasi pada masyarakat Indonesia secara umum. Perlu dipertimbangkan juga beberapa karakteristik lansia atau faktor lain yang dapat memengaruhi hasil penelitian TSK ini (NS, MK, INR).

\section{Ucapan Terima Kasih}

Terima kasih kepada DIKTI yang telah membiayai penelitian ini melalui skema Hibah Dosen Pemula 2013.

\section{Referensi}

Alosa Foundation. (2009). Independent drug information service. Diperoleh dari http:// www.rxfacts.org.

Baker, R., Holloway, J., Holtkamp, C., Larsson, A., Hartman, L., Pearce, R.,\& Owens, M. (2003). Effects of multi-sensory stimulation for people with dementia. Journal of Advanced Nursing, 43(5), 465-477. doi: 10.1046/j.13652648.2003.02744.x

Breuil, V., De Rotrou, J., \& Forette, F. (1994). Cognitive stimulation of patients with dementia: Preliminary results. International Journal of Geriatric Psychiatry, 9, 211-17. doi: 10.1002/gps.930090306

Brodaty, H., Green, A., \& Koschera, A. (2003). Metaanalysis of psychosocial interventions for caregivers of people with dementia. The American Geriatrics Society, 51, 657-664. doi: 10.1034/j.1600-0579.2003.00210.x

Brooker, D., \& Duce, L. (2000). Wellbeing and activity in dementia: A comparison of group reminiscence therapy, structured goal-directed group activity and unstructured time. Aging \&Mental Health, 4 (4), 354-8. doi: http://dx.doi.org/10.1080/713649967

Clare, L., \& Woods, R.T. (2004). Cognitive training and cognitive rehabilitation for people with early-stage Alzheimer's disease: A review. Neuropschological Rehabilitation, 14 (4), 385-401. doi: 10.1002/14651858.CD003260

Cormier S., Nurius, P.S., \& Osborn, C. J. (2012). Interviewing and change strategies for helpers (7th Ed.). Boston: Brooks/Cole Cengage Learning.

Eloniemi-Sulkava, U., Notkola, I., Hentinen, M., Kivela, S., Svenius, J., \& Sulkava, R. (2001). Effects of supporting community-living demented patients and their caregivers: A randomised trial. Journal of American Geriatrics Society, 49, 1281-1287. doi: http://onlinelibrary.wiley.com/doi/10.1111/jgs. 2001.49.issue-10/issuetoc 
FKIK UPH. (2013). Survey mahasiswa program profesi ners angkatan III. Banten: Fakultas Ilmu Keperawatan dan Ilmu Kesehatan, Universitas Pelita Harapan.

Folstein, M.F., Folstein, S.E. \& McHugh, P.R. (1975). Mini-mental state: A practical method for grading the cognitive state of patients for the clinician. Journal of Psychiatric Research, 12, 189-198. doi: http://dx.doi.org/10.1016/00223956(75) $90026-6$

Healy, J. (2004). The benefits of an ageing population. TheAustralia Institute Discussion Paper Number, 63, 1-41. doi: $10.1017 / \mathrm{S} 1041610212001822$.

Kementerian Sosial Republik Indonesia. (2010). Government targeted 2020 elderly welfare. Diperoleh dari http://www.kemsos.go.id.

Livingston, G., Johnston, K., Katona, C., Paton, J., \& Constantine, G. (2005). Systematic review of psychological approaches to the management of neuropsychiatric symptoms of dementia. Am J Psychiatry, 1, 1996-2021. doi: http://dx.doi.org/10.1176/appi.ajp.162.11.1996

Orrell, M., Yates, L.A., Burns, A., Russell, I., Woods, R.T., Hoar, Z., \&Orgeta, V. (2012). Individual cognitive stimulation therapy for dementia (ICST): Study protocol for a randomized controlled trial. BMC Trials, 13, 172.

Schneider, Z., Whitehead, D., Elliott, D., Lobiondo-Wood, G., \&Haber, J. (2007). Nursing and midwifery research, methods and appraisal for evidence-based practice (3rd Ed.). New South Wales: Elsevier.

Spector, A., Orrell, M., Davies, S., Woods, B. (2001). Can reality orientation be rehabilitated? Development and piloting of an evidence-based programme of cognition-based therapies for people with dementia. Neuropsychological Rehabilitation, 11(3-4), 377-379. doi: 10.1080/09602010143000068

Spector, A., Thorgrimsen, L., Woods, B., Royan, L., Davies, S., Butterworth, M., \& Orrell, M. (2003). Efficacy of an evidence-based cognitive stimulation therapy programme for people with dementia, randomised controlled trial. British Journal of Psychiatry, 183, 248254.doi: 10.1192/bjp.183.3.248

Spector, A., Thorgrimsen, L., Woods, B., \& Orrell, M. (2006). Making a difference-an evidenced based group programme to offer cognitive stimulation therapy (CST) to people with dementia: The manual for group leaders. Hawker Publications. Diperoleh dari http://www.communitycare.co.uk.

Spector, A., Orrell, M., \& Woods, B. (2010). Cognitive stimulation therapy (CST): Effects on different areas of cognitive function for people with dementia. International Journal Geriatric Psychiatry, 25, 1253-1258. doi: 10.1017/S1041610212001822.

Streater, A., Spector, A., Aguirre, E., Hoe, J., Hoare, Z., Woods, R., Russell, I., \& Orrell, M. (2012). Maintenance Cognitive Stimulation Therapy (CST) in practice: study protocol for a randomized controlled trial. BMC Trials, 13, 91. doi: 10.1186/1745-6215-13-91.

The Evidence-Base (2013). Cognitive Stimulation Therapy. Diperoleh dari http://www.cstdeme ntia.com/page/the-evidence-base.

United States Census Bureau. (2010). Age and sex. Diperoleh

darihttp://www.census.gov/population/age.

Videbeck, S.L. (2008). Buku ajar keperawatan jiwa.(R. Komalasari \& A. Hany, Penerj). Philadelphia: Lippincott Williams \& Wilkins Inc.(Buku asli diterbitkan tahun 2001).

Woods, B., Aguirre, E., Spector, A.E., \&Orrell, M. (2012). Cognitive stimulation to improve cognitive functioning in people with dementia. Cochrane Database of Systematic Reviews, 2, 1-78. doi: 10.1002/14651858.

Woods, R.T., Bruce, E., Edwards, R.T, Hounsome, B., Keady, J., Moniz-Cook, E.D., Orrell, M., \& Russell, I.T. (2009). Reminiscence groups for people with dementia and their family carers: Pragmatic eight-centre randomised trial of joint reminiscence and maintenance versus usual treatment: A protocol. BMC mTrials, 10, 64. doi: 10.1186/1745-6215-10-64 
